\title{
What do South African adolescents want in a sexual health service? Evidence from the South African Studies on HIV in Adolescents (SASHA) project
}

\author{
P Smith, ${ }^{1}$ MSocSci; R Marcus, ${ }^{1}$ BSc, MB ChB, MRCP (UK); T Bennie, ${ }^{1}$ MA; B Nkala, ${ }^{2}$ MA; M Nchabeleng, ${ }^{3}$ MB ChB; $\mathbf{M}$ H Latka, ${ }^{4} \mathrm{PhD}$; \\ G Gray, ${ }^{2}$ MB BCh, FCPaed; M Wallace, ${ }^{5}$ PhD; L-G Bekker, ${ }^{1}$ MB ChB, DCH, DTM\&H, FCP (SA), PhD
}

\author{
${ }^{1}$ Desmond Tutu HIV Centre, Institute for Infectious Disease and Molecular Medicine, Faculty of Health Sciences, University of Cape Town, South Africa \\ ${ }^{2}$ Perinatal HIV Research Unit and School of Human and Community Development, Faculty of Humanities, University of the Witwatersrand, \\ Johannesburg, South Africa \\ ${ }^{3}$ MeCRU Clinical Research Unit, Sefako Makgatho Health Sciences University, Pretoria, South Africa \\ ${ }^{4}$ Aurum Institute, Johannesburg, South Africa \\ ${ }^{5}$ Cancer Association of South Africa, Cape Town, South Africa
}

Corresponding author: P Smith (philip.smith@hiv-research.org.za)

\begin{abstract}
Background. Young people in sub-Saharan Africa (SSA) are disproportionately affected by HIV, sexually transmitted infections and unplanned pregnancies. The provision of accessible sexual and reproductive health services (SRHS) for young people in SSA is vital to reduce this burden.

Objectives. To examine the needs of South African (SA) adolescents with regard to differentiated, accessible and adolescent-responsive SRHS Methods. Data were drawn from a larger project examining the feasibility of conducting HIV vaccine trials in adolescents. Fifteen focus group discussions were conducted across five research sites in four SA provinces with 120 male and female adolescent human papillomavirus vaccine trial participants aged 12 - 19 years from low-income areas with a high incidence of HIV. Transcribed data were double-coded using framework analysis.

Results. Three main themes emerged on how best to improve SRHS for adolescents in resource-limited settings: adolescent-friendly services, availability of developmentally appropriate and tailored information, and improved relationships between healthcare workers and clinic attendees. Participants wanted more flexible opening hours at SRHS to account for travel time to clinics from school and home. They suggested that services include contraception, counselling, educational materials, links to adoption services, emergency vehicles, pre- and postnatal care, and improved service quality from clinic staff.

Conclusions. While dedicated adolescent SRHS might best meet the needs of young people in SA, the study suggests that failing this, existing SRHS should be more responsive to adolescent use. Innovations such as mobile outreach services, self-testing and flexible hours will help SRHS respond to adolescents' needs.
\end{abstract}

S Afr Med J 2018;108(8):677-681. DOI:10.7196/SAMJ.2018.v108i8.13013

South African (SA) adolescents are at substantial risk of HIV infection, in part because of the psychosocial and biological transitions experienced during this developmental phase while living in an area of high HIV burden. ${ }^{[1,2]}$ While HIV incidence and HIV-related deaths have decreased in other populations in sub-Saharan Africa (SSA), HIV-related deaths among adolescents continue to rise. ${ }^{[3-5]}$ The development of sexual identity and sexual debut during this period are associated with the risk of sexually transmitted infections ${ }^{[5,6]}$ and unplanned pregnancies, with $18 \%$ of 10 - 19 -year-olds and $27 \%$ of 15 - 26-year-olds in SA reporting at least one pregnancy. ${ }^{[7,8]}$

Adolescents are keen to become better informed about sex and its potential consequences, but they may avoid healthcare services because of both real and perceived barriers..$^{[1,5,9-14]}$ While some adolescents visit general practitioners for their sexual and reproductive health needs, ${ }^{[15]}$ many are unaware of the range or location of clinics offering sexual and reproductive health services (SRHS) ${ }^{[6]}$ Barriers to accessing healthcare include fragmented healthcare services, long travelling and waiting times, and concerns about interactions with healthcare staff, such as fear of embarrassment, interactions with judgemental staff, loss of confidentiality and privacy, and being examined. ${ }^{[14,16,17]}$ The availability of differentiated, welcoming and accessible SRHS for adolescents must be prioritised in order to address the needs of young people. ${ }^{[18]}$

A systematic review of adolescent-friendly services in SSA reported on the gap between numbers of HIV-affected youth (either those at risk of HIV or those living with HIV) and the interventions available to support them. ${ }^{[19]}$ Systematic reviews from SA point to non-judgemental provider interaction and confidentiality as primary desirable characteristics for youth-friendly services. ${ }^{[5,20]}$ In response, the National Adolescent Friendly Clinic Initiative (NAFCI) was developed in SA between 1999 and 2006 to support clinics to provide more adolescent-friendly services. ${ }^{[5,6]}$ The NAFCI received mixed reviews, in that while the clinics earmarked as adolescentfriendly clinics were considered more responsive in the provision of adolescent services, adolescents did not report an increase in positive interactions with staff. ${ }^{[21]}$ The NAFCI was subsequently discontinued, primarily owing to lack of sustained funding. ${ }^{[22-24]}$ More than 20 years into the SA HIV epidemic, the present generation of youth has not known a world without HIV and it is important to examine their concerns, needs and perceptions regarding sexual 
and reproductive health and HIV prevention and treatment services such as HIV counselling and testing, referral to antiretroviral therapy and pre-exposure prophylaxis (PrEP), and voluntary male medical circumcision (VMMC).

\section{Objectives}

The present study was a sub-study of a larger project, the South African Studies on HIV in Adolescents (SASHA), studying the feasibility of conducting HIV vaccine trials in adolescents. ${ }^{[25]}$ Given the importance of youth engagement in the provision of user-friendly services for this population, the present project set out to investigate adolescent preferences for differentiated SRHS with the ultimate aim of finding innovative ways to incorporate adolescent-friendly services into already existing healthcare infrastructure.

\section{Methods}

Data were collected from adolescent focus group discussions (FGDs) with participants from around SA. Prior to the FGDs, participants gave their written informed consent, including consent for audio recordings of the FGD. Parental consent was sought for participants aged $<18$ years at the time of participation.

\section{Sample and setting}

The research was conducted at five clinical research sites in SA: the Desmond Tutu HIV Foundation's Emavundleni clinical research site in Crossroads, Cape Town; the Centre for the AIDS Programme of Research in South Africa in Durban; the Perinatal HIV Research Unit in Soweto, Johannesburg; MeCRU Clinical Research Unit at Sefako Makgatho Health Sciences University (the former Medunsa Campus of the University of Limpopo) in Pretoria; and the Aurum Institute in Klerksdorp and Rustenburg. These research sites are located in predominantly low-income areas with a high HIV incidence. Ethical approval for the study was granted by each site's institutional review board (University of Cape Town ref. no. 245/2008, University of the Witwatersrand ref. no. 080710, University of KwaZulu-Natal ref. no. BF109/08, University of Limpopo ref. no. MREC/P/110/2009). Adolescents aged between 12 and 17 years were recruited for the FGDs from the main cohort study, which used community outreach activities in sports clubs, transport hubs, community centres, HIV voluntary counselling and testing services and other public spaces. Since it was anticipated that the needs of younger and older adolescents and of males and females might differ, participants were given the choice between attending age-specific and single-sex discussion groups, or mixed groups. There were 15 FGDs with a total of 120 participants (54 male, 60 female, 6 unspecified) across five sites (Table 1).

Trained community educators conducted the FGDs at the research sites. A facilitator presented 10 questions designed to gauge adolescent perspectives on adolescent-friendly healthcare services, and group members generated and explored their own understandings of what kind of healthcare services were required for good sexual health.

Conceptual mapping was used to facilitate discussion of adolescents' opinions. This process requires participants to map responses on paper by grouping similar desirable characteristics together. ${ }^{[26]}$ The requirements of a sexual health service were grouped according to services desired (e.g. pregnancy testing) and characteristics of that service (e.g. non-judgemental atmosphere). Participants were asked to explain the rationale underlying the organisation of their responses. This method has been particularly helpful in initiating and focusing discussion around sensitive topics, and in eliciting information from participants who tend to be visually orientated. ${ }^{[26]}$ In this study, conceptual mapping identified characteristics of an adolescent-friendly healthcare service, and allowed participants the freedom to generate their own values on the discussion topic.

\section{Data analysis}

The FGDs were conducted in the local languages and were audio recorded. After the audio was transcribed, the transcriptions were translated into English. Nine representatives from the five sites were trained to code the FGDs, develop coding charts and map the data. Double-coded charts were analysed using the framework method of analysis. This provided a procedural structure for organising data into key emerging themes to support data familiarisation, identification of themes, indexing themes and data interpretation. Coders held regular calls throughout the analysis process to ensure consistent coding and to discuss emerging themes and adapt coding charts.

\section{Results}

\section{Overview of the focus group discussions: Four themes}

The data from the focus group discussions were framed into the following four categories: $(i)$ the need for the provision of dedicated adolescent health services; (ii) tailored services with developmentally appropriate information; (iii) emphasis on the desire for confidentiality and trusting relationships with healthcare staff; and (iv) greater emphasis on appropriate services required at an adolescent clinic.

\section{Dedicated adolescent services}

Participants expressed negative sentiments about the routine care young people experience at government clinic facilities, reporting that clinic opening times were inflexible, that staff could be unpleasant, stigmatising and often rude, and that staff did not respect confidentiality and gave inappropriate and misleading information. One participant noted:

'Because most young people are disturbed already, a young person is not able to go to the public clinic because nurses there are very rude.' (Female, 16 - 17)

\section{Table 1. Summary of participants per site}

\begin{tabular}{llll}
\hline Location $(\boldsymbol{n}$ FGDs) & $\begin{array}{l}\text { Group 1 (mixed groups), } \\
\text { age (years), } \boldsymbol{n}\end{array}$ & $\begin{array}{l}\text { Group 2 (female groups), } \\
\text { age (years), } \boldsymbol{n}\end{array}$ & $\begin{array}{l}\text { Group 3 (male groups), } \\
\text { age (years), } \boldsymbol{n}\end{array}$ \\
\hline DTHF (2) & $12-17,11(5 \mathrm{f}, 6 \mathrm{~m})$ & - & $12-15,6$ \\
PHRU (4) & $12-15,6$ (unspecified) & $2 \times 12-15,9$ and 8 & $15-17,10$ \\
KOSH (3) & $12-15,5(4 \mathrm{f} 1 \mathrm{~m})$ & $15-17,6$ & $12-16,5$ \\
CAPRISA (3) & $15-17,11(5 \mathrm{f}, 6 \mathrm{~m})$ & $16-17,11$ & $12-15,8$ \\
MeCRU (3) & $15-17,8(4 \mathrm{f}, 4 \mathrm{~m})$ & $12-15,8$ & $15-17,8$
\end{tabular}

DTHF $=$ Desmond Tutu HIV Foundation's Emavundleni clinical research site in Crossroads, Cape Town; CAPRISA = Centre for the AIDS Programme of Research in South Africa in Durban PHRU = the Perinatal HIV Research Unit in Soweto, Johannesburg; MeCRU = the MeCRU at Sefako Makgatho Health Sciences University (the former Medunsa Campus of the University of Limpopo) in Pretoria; $\mathrm{KOSH}=$ the Aurum Institute in Klerksdorp and Rustenburg; $\mathrm{f}=$ female; $\mathrm{m}=$ male. 
Participants universally agreed that friendly adolescent services were needed. They suggested that dedicated services would result in less discrimination towards younger people, with a reduction in perceived and actual stigma. Participants were enthusiastic about the concept of dedicated adolescent health services and reported that adolescent services would '... change people's lives in regard to the issue of assistance in the clinic'. Participants also stated that they would feel more comfortable and '... free with their own age group who are understanding.

'It's okay if we will not feel shy and become free, if we can be understood by staff. Younger staff can understand challenges facing adolescents and address our issues as adolescents. They must be able to talk to people. One can go to the clinic and find that there are staff that are not kind or sensitive.' (Male, 15 - 17)

\section{Tailored services}

Adolescents wanted tailored information and services directed at their specific developmental stage. Didactic and punitive commands issued by clinic staff were specifically noted as being unhelpful. Participants felt that staff could encourage healthy behaviour if they were open to listening to young people, could connect with common issues faced by adolescents, could give relevant practical advice, and could suggest ways of navigating potential barriers to health. The suggestion of younger staff and possibly peers to act as guides to help navigate the services was also made. Group members noted that it was important for information to be appropriate for their age and tailored to their needs.

'As for me, I would feel much better that I am going to the youth clinic than going to a community clinic because I will be able to even get tested for HIV because I would feel more comfortable than going to the adult clinic ... I also think that it will be something right to have a youth clinic because you will be comfortable to speak with the people.' (Female, 16 - 17)

'Our clinic needs to have young staff to welcome us and be able to talk to us in an appropriate manner and treat us with respect and care. To have people who know how to talk to young people if they are traumatised.' (Male, 12 - 15)

'They need to talk to the counsellor or people who know these issues, because if they go to traditional healers they will get herbs that are not good.' (Male, 12 - 15)

\section{Relationships: Confidentiality and trust}

When asked about what they wanted from a healthcare service, participants noted that trust in staff and health facilities is an important factor. Participants reported that health facilities are daunting places where they may see people they know, leading to actual or perceived loss of confidentiality. Adolescents specifically feared that their parents would find out that they had attended a clinic, which consequently discouraged attendance. Participants stated that mistrust leads to less honest sharing of information, but that trusting relationships would foster honest conversation with healthcare professionals.

'I think that you end up changing the story, as you enter through the door you say no, I will tell the truth, but then when sitting down with the person you change the story because when the nurse you talk with is about to go through the door, she is telling another nurse who is in another room, "But the children of today they are like this, look at the one here, [she] has slept with boyfriends", but there are people there at the same time ... by the time you go out that door you are known to be sexually active or pregnant at the age of 13 or so.' (Female, 16 - 17)
Adolescents thought that dedicated services could provide adolescents with safe spaces to share their issues and problems with staff without fear of reproach, with one participant stating: '... it will help people to feel safe emotionally and physically'.

Adolescents said they were unlikely to '... go if they feel judged' or if older people lectured them and spread rumours about them. They felt that their sexual behaviour was stigmatised and that they were therefore not fully informed of their options by clinic staff. Participants feared clinic staff and felt uncomfortable disclosing sexual activity and asking healthcare staff for services.

\section{Availability of services and information}

Participants were most vocal about contraception services and related education, stating that these services should be available and confidential. Additionally, they were interested in individualised contraception options, instead of receiving a 'one-size-fits-all' approach. It was suggested that women should have access to private rooms where contraception can be made available. Adolescents recognised the need for accurate information in making health decisions, with a female participant commenting: '... it is better to get information from experienced adults like your mother or health staff'. However, participants reported that information given to adolescents visiting traditional facilities was not always age-appropriate and was sometimes inaccurate. Participants believed that clinic staff did not always present them with all the information, or all the available options. They said that healthcare staff should be up to date, to enable them to provide reliable, tailored and relevant information. Additionally, participants indicated that sexual and reproductive health should provide pre- and postnatal care, information about adoption services and emergency vehicles. They stated that it was important to receive counselling around contraception and prevention of sexually transmitted infections (STIs). The suggestion was made that counselling be available for adolescents who needed rehabilitation for drug use.

\section{Discussion}

While FGD participants expressed the need for distinct adolescent clinics, many of their requirements could be met via adaptations in mainstream clinic services if these were to be provided with youth needs in mind, such as the adoption of peer navigators as a standard cadre of staff in clinics servicing youth. Adolescent clinic attendees regularly report poor experiences at health facilities and feeling discriminated against. These experiences create mistrust between this age group and healthcare providers, which may lead to inappropriate or inadequate care. If young people do not use SRHS owing to negative perceptions of these facilities, the opportunity for HIV, STI and pregnancy prevention and care is lost.

The content of the FGDs aligned with previous qualitative data on adolescents' desires for adequate healthcare services. ${ }^{[12,27-30]}$ It was clear that young people want accurate, age-appropriate health information and client-centred care. They want to talk openly and ask questions without fear of being stigmatised or judged. Participants spoke in depth about the quality of care being enmeshed in trusting relationships between service users and healthcare professionals. They also spoke at length about the difficulties of expressing themselves to healthcare staff, and emphasised the need for spaces where they could speak openly to people who they felt could relate to them. In addition, the participants wanted accessible and relevant services that preserve their privacy and confidentiality. These youth-friendly spaces may increase health-seeking behaviour. 
While the study findings may have good generalisability because the data were collected from a variety of locations across SA, the adolescents and parents who were willing to participate in research into acceptability of a vaccine for an STI may be more open than the general population. Willingness to participate in sexual health research may indicate that this was a subset of the general population who were relatively informed and forward-thinking regarding sexual health.

The NAFCI attempted to address a number of the issues that were raised by the participants in this study, including the provision of sensitivity training to NAFCI staff, the provision of a youth-friendly space, and accompanying peer support through youth 'ground breakers' provided by the LoveLife HIV prevention project. ${ }^{[24]}$ However, the scale-up and sustained presence at government clinics were challenging owing to lack of co-ordination and resourcing in a decentralised health system in SA. ${ }^{[22,23]}$ Analysis of the NAFCI showed that while adolescents were more likely to receive HIV testing at NAFCI clinics, the overall experience of these clinics was no more positive than at non-NAFCI clinics, because patient-provider relationships, confidentiality and the appropriateness of counselling services were rated similarly at NAFCI and non-NAFCI clinics. ${ }^{[5,21]}$ Adolescent-friendly services should specifically address these important issues to attract more adolescent visitors. Adolescents who had participated in two or more LoveLife programmes were less likely than other adolescents to acquire HIV infection, ${ }^{[31]}$ and NAFCI clinics were more likely than non-NAFCI clinics to provide HIV testing to adolescents. The valuable lessons learned from NAFCI could inform future investigations and the implementation of scalable and sustainable innovations for adolescent-responsive healthcare.

The results of this study are relevant to objectives 2 and 3 of the SA youth health policy, specifically the recommendation for the provision of adolescent-friendly services including comprehensive and integrated SRHS and HIV prevention, testing and treatment services. Adolescent-responsive health services with 'youth zones' have the potential to encourage regular health-seeking and prevent unwanted outcomes in adolescents. These spaces could also be used to offer additional biomedical prevention services, such as PrEP and VMMC as recommended in the SA guidelines.

Future implementation research should focus on bringing the lessons learnt from previous initiatives and qualitative data together in a service that meets young people at the point of their need, rather than a replication of adult healthcare services. Emphasising aspects of confidentiality and non-judgemental staff could attract more youth to services, particularly those services most relevant to young people. This could be done by having clinic-based or communitybased peer navigators who themselves have been well-trained youth, or are young adults who demographically match or are close to the adolescent target population. Stationed at the clinic or deployed into the community, these youth could relay the message that the clinic is different, non-judgemental and trustworthy, while also helping adolescents understand what services are available and how best to use them. Differentiated healthcare delivery methods such as self-testing and mobile clinics should be explored to improve HIV testing uptake, which is increasingly the gateway to healthcare services in communities with limited resources. Mobile services are preferred by young people, are cost-effective, and can be monitored to direct the clinic to communities most in need of the service. ${ }^{[32-34]} \mathrm{HIV}$ self-testing is reported as being more accessible and less time consuming by youth users. ${ }^{[35]}$ Healthcare services could also consider the use of mobile technology to extend the patientprovider relationship and communicate with patients based on their personal health profile. ${ }^{[36]}$ This technology could be incorporated into existing services, and could rely on instant messaging platforms that are relatively inexpensive. Individualised care has been found to be more acceptable to adolescents than general services. ${ }^{[27,37]}$ Additionally, future research could investigate the effects of a gainframed, wellness-centred approach to behaviour change that builds a sense of autonomy and competence through providing responsive sexual and reproductive health options for adolescents. Finally, cost, feasibility and scalability should be urgently investigated to ensure that such programmes are adopted, integrated and become entrenched in national public health provision.

Young people are concerned with their health, but are put off by visits to traditional adult clinic facilities, which are stigmatising, time consuming and unhelpful. Taken together, the results of this study suggest that adolescents would benefit from differentiated models of care, including diagnostics, counselling, and tailored support through adolescent-directed sexual health options for prevention, treatment and care. Since dedicated adolescent services may only be a future consideration, adolescents may benefit from the implementation of scalable and integrated SRHS within the existing health infrastructure. Successfully integrated, adolescent-friendly HIV prevention and sexual reproductive health services can in turn provide a gateway to lifelong healthy adult engagement with health services.

\section{Acknowledgements. None.}

Author contributions. L-GB, GG and MW conceptualised the study. L-GB, GG, MW, BN, MN, TB and MHL contributed to the study design. MW, $\mathrm{BN}, \mathrm{MN}, \mathrm{TB}$ and MHL were responsible for study operations and quality assurance. PS, TB, RM and MW conducted the data analysis and the interpretation of the data. All authors contributed to the analysis strategy and manuscript preparation. All authors approved the final version of the manuscript.

Funding. This study was funded by an EDCTP grant (project no. CT.200633111.004).

Conflicts of interest. None.

1. Bekker L-G, Johnson L, Wallace M, Hosek S. Building our youth for the future. J Int AIDS Soc 2015;18(2 Suppl 1):20027. http://doi.org/10.7448/IAS.18.2.20027

2. Pettifor A, Bekker L-G, Hosek S, et al. Preventing HIV among young people: Research priorities for the future. J Acquir Immune Defic Syndr 2013;63(Suppl 2):S155-S160. https://doi.org/10.1097/ QAI.0b013e31829871fb

3. Delany-Moretlwe S, Cowan FM, Busza J, Bolton-Moore C, Kelley K, Fairlie L. Providing comprehensive health services for young key populations: Needs, barriers and gaps. J Int AIDS Soc 2015;18(2 Suppl 1):29-40. https://doi.org/10.7448/IAS.18.2.19833

Dellar RC, Dlamini S, Karim QA. Adolescent girls and young women: Key populations for HIV epidemic control. J Int AIDS Soc2015;18(2 Suppl 1):19408. https://doi.org/10.7448/IAS.18.2.19408 Geary RS, Gómez-Olivé FX, Kahn K, Tollman S, Norris SA. Barriers to and facilitators of the provision of a youth-friendly health services programme in rural South Africa. BMC Health Serv Res
2014;14(1):259. https://doi.org/10.1186/1472-6963-14-259

6. Dickson-Tetteh K, Pettifor A, Moleko W. Working with public sector clinics to provide adolescentfriendly services in South Africa. Reprod Health Matters 2001;9(17):160-169. https:/doi.org/10.1016/ 0968-8080(01)90020-5

7. Christofides NJ, Jewkes RK, Dunkle KL, Nduna M, Shai NJ, Sterk C. Early adolescent pregnancy increases risk of incident HIV infection in the Eastern Cape, South Africa: A longitudinal study. J Int AIDS Soc;17(1):18585. https://doi.org/10.7448/IAS.17.1.18585

8. Macleod CI, Tracey T. A decade later: Follow-up review of South African research on the consequences of and contributory factors in teen-aged pregnancy. S Afr J Psychol 2010;40(1):18-31. https://doi. org $/ 10.1177 / 008124631004000103$

9. Black S, Wallace M, Middelkoop K, et al. Improving HIV testing amongst adolescents through an integrated youth centre rewards program: Insights from South Africa. Child Youth Serv Rev 2014;45:98-105. https://doi.org/10.1016/i.childyouth.2014.03.025

10. Geary RS, Webb EL, Clarke L, Norris SA. Evaluating youth-friendly health services: Young people’s Geary RS, Webb EL, Clarke L, Norris SA. Evaluating youth-friendly health services: Young people's
perspectives from a simulated client study in urban South Africa. Glob Health Action 2015;8(1):26080. herspe://doi.org/10.3402/gha.v8.26080

11. Svanemyr I, Amin A, Robles OJ, Greene ME. Creating an enabling environment for adolescent sexual and reproductive health: A framework and promising approaches. J Adolesc Health 2015;56(1, Suppl):S7-S14. https://doi.org/10.1016/j.jadohealth.2014.09.011

12. Wood K, Jewkes R. Blood blockages and scolding nurses: Barriers to adolescent contraceptive use in South Africa. Reprod Health Matters 2006;14(27):109-118. https://doi.org/10.1016/S09688080(06)27231-8

13. Jewkes R, Morrell R, Christofides N. Empowering teenagers to prevent pregnancy: Lessons from South Africa. Cult Health Sex 2009;11(7):675-688. http://doi.org/10.1080/13691050902846452

14. Vujovic M, Struthers H, Meyersfeld S, Dlamini K, Mabizela N. Addressing the sexual and reproductive health needs of young adolescents living with HIV in South Africa. Child Youth Serv Rev 2014;45(Oct):122-128. https://doi.org/10.1016/j.childyouth.2014.03.028 
15. MacPhail C, Campbell C. 'I think condoms are good but, aai, I hate those things': Condom use among adolescents and young people in a southern African township. Soc Sci Med 2001;52(11):1613-1627. adolescents and young people in a southern Aftar
https://oi.org/10.1016/S0277-9536(00)00272-0

16. Mmari K, Marshall B, Hsu T, Shon JW, Eguavoen A. A mixed methods study to examine the influence of the neighborhood social context on adolescent health service utilization. BMC Health Serv Res 2016;16:433. https://doi.org/10.1186/s12913-016-1597-x

17. Wilson A, Williams R. Sexual health services: What do teenagers want? Ambul Child Health 2000;6(4):253-260. https://doi.org/10.1046/j.1467-0658.2000.00090.x

18. Dickson KE, Ashton J, Smith J-M. Does setting adolescent-friendly standards improve the quality of care in clinics? Evidence from South Africa. Int J Qual Health Care 2007;19(2):80-89. https://doi. org/10.1093/intqhe/mzlo70

19. Michielsen K, Chersich MF, Luchters S, de Koker P, van Rossem R, Temmerman M. Effectiveness of HIV prevention for youth in sub-Saharan Africa: Systematic review and meta-analysis of randomized and nonrandomized trials. AIDS 2010;24(8):1193-1202. https://doi.org/10.1097/QAD.0b013e3283384791

20. Zanoni BC, Archary M, Buchan S, Katz IT, Haberer JE. Systematic review and meta-analysis of the adolescent HIV continuum of care in South Africa: The cresting wave. BMJ Glob Health 2016;1(3):e000004. https://doi.org/10.1136/bmjgh-2015-000004

21. Mathews C, Guttmacher SJ, Flisher AJ, et al. The quality of HIV testing services for adolescents in Cape Town, South Africa: Do adolescent-friendly services make a difference? J Adolesc Health Cape Town, South Africa: Do adolescent-friendly services make
2009;44(2):188-190. https://doi.org/10.1016/j.jadohealth.2008.05.009

22. Pillay Y. The impact of South Africas new constitution on the organization of health services in the post-apartheid era. J Health Polit Policy Law 2001;26(4):747-766. https://doi.org/10.1215/0361687826-4-747

23. Schriver B, Meagley K, Norris S, Geary R, Stein AD. Young people’s perceptions of youth-oriented health services in urban Soweto, South Africa: A qualitative investigation. BMC Health Serv Res 2014;14:625. https://doi.org/10.1186/s12913-014-0625-y

24. Pettifor AE, MacPhail C, Bertozzi S, Rees HV. Challenge of evaluating a national HIV prevention programme: The case of LoveLife, South Africa. Sex Transm Infect 2007;83(Suppl 1):i70-i74. https:// doi.org/10.1136/sti.2006.023689

25. Wallace M, Middelkoop K, Smith P, et al. Feasibility and acceptability of conducting HIV vaccine trials in adolescents in South Africa: Going beyond willingness to participate towards implementation. S Afr Med J 2018;108(4):291-298. https://doi.org/10.7196/SAMJ.2018.v108i4.12909

26. Latka MH, Kapadia F, Fortin P. The female condom: Effectiveness and convenience, not 'female control,' valued by U.S. urban adolescents. AIDS Educ Prev 2008;20(2):160-170. https://doi. org/10.1521/aeap. 2008.20.2.160

27. Forrest JI, Kaida A, Dietrich J, Miller CL, Hogg RS, Gray G. Perceptions of HIV and fertility among adolescents in Soweto, South Africa: Stigma and social barriers continue to hinder progress. AIDS Behav 2009;13(Suppl 1):55-61. https://doi.org/10.1007/s10461-009-9552-2
28. MacPhail CL, Pettifor A, Coates T, Rees H. 'You must do the test to know your status': Attitudes to HIV voluntary counseling and testing for adolescents among South African youth and parents. Health Educ Behav 2008;35(1):87-104. https://doi.org/10.1177/1090198106286442

29. Ntsepe Y, Simbayi LC, Shisana O, et al. Perceptions about the acceptability and prevalence of Ntsepe $\mathrm{Y}$, Simbayi LC, Shisana $\mathrm{O}$, et al. Perceptions about the acceptability and prevalence of
HIV testing and factors influencing them in different communities in South Africa. SAHARA 2014;11(1):138-147. https://doi.org/1080/17290376.2014.937355

30. Tylee A, Haller DM, Graham T, Churchill R, Sanci LA. Youth-friendly primary-care services: How are we doing and what more needs to be done? Lancet 2007;369(9572):1565-1573. https://doi.org/10.108 0/17290376.2014.937355

31. Pettifor A, Rees HV, Kleinschmidt I, et al. Young people’s sexual health in South Africa: HIV prevalence and sexual behaviors from a nationally representative household survey. AIDS 2005;19(14):1525-1534. https://doi.org/10.1097/01.aids.0000183129.16830.06

32. Mavedzenge SN, Baggaley R, Corbett EL. A review of self-testing for HIV: Research and policy priorities in a new era of HIV prevention. Clin Infect Dis 2013:57(1)126-138. https://doi.org/10.1093/ cid/cit156

33. Bassett IV, Govindasamy D, Erlwanger A, et al. Mobile HIV screening very cost effective in South Africa. Pharmacoeconomics Outcomes News 2013;676(1):10-10. https://doi.org/10.1007/s40274-013Africa.

34. Bassett IV, Govindasamy D, Erlwanger AS, et al. Mobile HIV screening in Cape Town, South Africa: Clinical impact, cost and cost-effectiveness. PLoS One 2014;9(1):e85197. https://doi.org/10.1371/ journal.pone. 0085197

35. Smith P, Wallace M, Bekker L-G. Adolescents' experience of a rapid HIV self-testing device in youthfriendly clinic settings in Cape Town South Africa: A cross-sectional community based usability study. J Int AIDS Soc 2016;19(1):21111. https://doi.org/10.7448/IAS.19.1.21111

36. Perry RCW, Kayekjian KC, Braun RA, Cantu M, Sheoran B, Chung PJ. Adolescents' perspectives on the use of a text messaging service for preventive sexual health promotion. J Adolesc Health 2012;51(3):220-225. https://doi.org/10.1016/j.jadohealth.2011.11.012

37. Kaufman MR, Smelyanskaya M, van Lith LM, et al. Adolescent sexual and reproductive health services and implications for the provision of voluntary medical male circumcision: Results of a systematic literature review. PLoS One 2016;11(3):e0149892 . https://doi.org/10.1371/journal.pone.0149892

Accepted 23 February 2018 